\title{
Spasmodic torticollis - a multicentre study on behavioural aspects III: psychosocial changes and coping
}

\author{
T. Nickel ${ }^{1}$, F. Heinen ${ }^{2}$, C.E. Scheidt ${ }^{1}$, O. Rayki ${ }^{1}$, J. Wisse $^{3}$, W. Poewe ${ }^{3}$, \\ R. Benecke ${ }^{4}$, T. Gasser ${ }^{5}$, W. Oertel ${ }^{5}$, R. Dengler ${ }^{6}$ and G. Deuschl ${ }^{2}$
}

\begin{abstract}
${ }^{1}$ Abteilung für Psychotherapie und Psychosomatik, Universität Freiburg, ${ }^{2}$ Neurologische Klinik und Poliklinik, Universität Freiburg, ${ }^{3}$ Neurologische Klinik, Rudolf-Virchow-Krankenhaus, Humboldt-Universität Berlin, ${ }^{4}$ Neurologische Klinik, Universität Düsseldorf, ${ }^{5}$ Neurologische Klinik, Ludwig-Maximilians-Universität München, ${ }^{6}$ Neurologische Klinik, Medizinische Hochschule Hannover, Germany
\end{abstract}

Correspondence to: T. Nickel and C.E. Scheidt, Department of Psychotherapy and Psychosomatic Medicine, University of Freiburg, Hauptstr. 8, 79104 Freiburg, Germany

\begin{abstract}
Psychosocial changes in spasmodic torticollis (ST) affect predominantly social life, professional life and psychological wellbeing. Concerning social life, $84.6 \%$ of the patients felt that they attracted considerable public attention due to their neurological illness and $65 \%$ had reduced participation in social events. A substantial number of patients had retired from professional activities; others felt severely impaired in their working capacity. The psychosocial sequelae in ST, however, seemed to depend less on the neurological signs per se than on the physical symptoms and on coping. Depressive coping in particular emerged as a predictor of psychosocial distress.
\end{abstract}

Keywords: Spasmodic torticollis - Neurologic symptoms - Coping - Psychosocial changes

\section{INTRODUCTION}

In spite of the improvement in treatment by the use of botulinum toxin within recent years, spasmodic torticollis (ST) takes a chronic course in the majority of patients. The visible, sometimes even disfiguring, symptomatology may entail severe psychosocial changes and require considerable efforts in coping.

As reported in the preceding paper (Heinen et al., 1996), compared to a control group with cervical spondylosis, Jahanshahi and Marsden (1988, 1990a,b) found increased depression scores in ST. The authors considered the depressive symptoms to be related to disfigurement (see Scheidt et al., 1996). Halbgewachs and Aschoff (1992), Matthews et al. (1978) and others have also described negative effects of ST on social, professional and everyday life. In addition to the functional impairment affecting everyday and professional life, profound changes were reported to occur in social relations. According to Rentrop and Straschill (1982) 28 of the 37 patients in their sample indicated almost complete retreat from public and social relationships and limitation of their social contacts to the immediate family.
As mentioned earlier, few studies so far have investigated coping strategies in ST. Jahanshahi (1991) reported that cognitive and emotion-focused coping strategies dominate in ST, compared to instrumental ways of coping (in the Ways of Coping Checklist by Folkman and Lazarus, 1980). The coping strategies mainly applied were threat-minimization, wishful thinking and cognitive restructuring; by contrast, positive reappraisal, religious faith and instrumental coping were less frequent (Jahanshahi, 1991). Wishful thinking and religious faith in that study were related to depression. The results demonstrate that coping may be relevant in ST not only to social adjustment but also to psychological dysfunction.

In this paper three questions outlined in the first paper in this series (see Scheidt et al., 1996) will be addressed. What are the predominant psychosocial changes due to ST, if any, and what areas of life (professional, family, social and everyday life) are mainly affected? Are these psychosocial changes related to specific features of the neurological condition? What coping mechanisms are used in ST and do 
psychosocial changes depend on specific patterns of coping?

\section{RESULTS}

\section{Psychosocial changes}

The psychosocial changes are described on item-level first, reporting on each area of life separately. The frequencies summarize two or more rating categories, which refer to the five-point rating scale used in the Freiburg Questionnaire for Dystonia (FQD) (see Scheidt et al, 1996).

Professional life. Changes in this area are reflected in a large number of retirements which had taken place in 56 patients $(23.4 \%$ of the total sample). Thirty-seven patients $(14.4 \%$ of the total sample) were on sick leave at the time of the study. Of the 119 patients who were still working, $51.3 \%$ felt severely or very severely impaired in their professional activities. A comparable proportion $(50.5 \%)$ had severe or very severe doubts concerning their future professional career; $33.1 \%$ of the patients reported financial losses as a result of their disease (categories 3-5). Of the total, $53.4 \%$ had considerably curtailed their contacts with colleagues (categories 3-5).

Everyday life. In everyday life, $64.4 \%$ of the patients showed disabilities in performing their household chores (categories 3-5), and $51 \%$ in undertaking spare-time activities such as reading or watching television (categories 3-5). Driving a car was affected in $59.5 \%$ (categories 3-5). Of the patients $55.3 \%$ felt disabled as pedestrians (categories 3-5) or using public transport ( $42.4 \%$ categories $3-5)$.

Social life. Disfigurement plays a particular role in social life. Of the patients $84.6 \%$ felt that they attracted considerable public attention (categories 35). Sixty-five per cent had reduced their participation in public events (categories 4 and 5), premorbid contacts with friends and acquaintances had decreased in $19.2 \%$ (categories 4 and 5). Of the patients $79.9 \%$ reported being affected in spare-time activities involving social contacts (categories 3-5). Due to the changes in their social life, $49.6 \%$ of the patients felt socially isolated (categories 3-5).

Family life. Compared with the other areas, relatively minor changes occurred in the patients' family life. These affected mainly family events $(28.9 \%$ categories 4 and 5) and changes in the distribution of tasks within the family (23.4\% categories 4 and 5).
However $25.5 \%$ reported a moderate to very severe deterioration of the family atmosphere; and $21.7 \%$ of the families were moderately to very severely affected by financial losses.

Psychological well-being. The patients were asked whether their psychological well-being had changed compared to the time before the beginning of their illness. The following percentages refer to the rating categories 3-5: depression (63.6\%), feeling of reduced attractiveness $(64.4 \%)$ irritability $(54.9 \%)$, anxiety $(62.6 \%)$, feeling less assertive $(55.5 \%)$.

As described in our first paper (Scheidt et al., 1996), the individual ratings of the different areas were summarized to item-standardized scales. The mean values of the scales indicate roughly the severity of the psychosocial changes in the respective area of life. As can be seen from Fig. 1 three areas of life are particularly affected. These are social life $(1.97, \mathrm{SD}=0.9)$, professional life $(1.82, \mathrm{SD}=0.9)$ and psychological well-being $(1.90, \mathrm{SD}=0.9)$, whereas everyday life and family life are slightly less impaired.

Women felt more severely disabled in daily life than men $(p<0.01)$; family life was reported by men to be more severely affected $(p<0.05)$. No significant differences between the sexes were found in any other area.

Psychosocial changes do not affect all patients equally. Referring to social life for example, $34 \%$ of the patients reported no or very minor changes (categories 1 and 2) in their participation in social events and $50.4 \%$ did not feel socially isolated at all due to the disease.

\section{Coping}

Figure 2 shows mean values and standard deviations of the preferred coping strategies in the Freiburger Questionnaire for Coping (FKV). Active problemfocused coping was most frequent.

This coping strategy includes activities and attitudes such as planned problem solving, search for information, will and stamina but also an attitude of compensatory life enjoyment. Self-distraction and encouragement ranked second. These include strategies of cognitive distraction as well as positive self-instruction. Religious faith and search for meaning ranked third. Items of this scale ask about comfort found in religious faith, acceptance of the disease as a fate, the search for meaning in life and the pursuit of altruistic ideas.

Depressive coping as well as minimization and wishful thinking were equally frequent. Depressive coping 


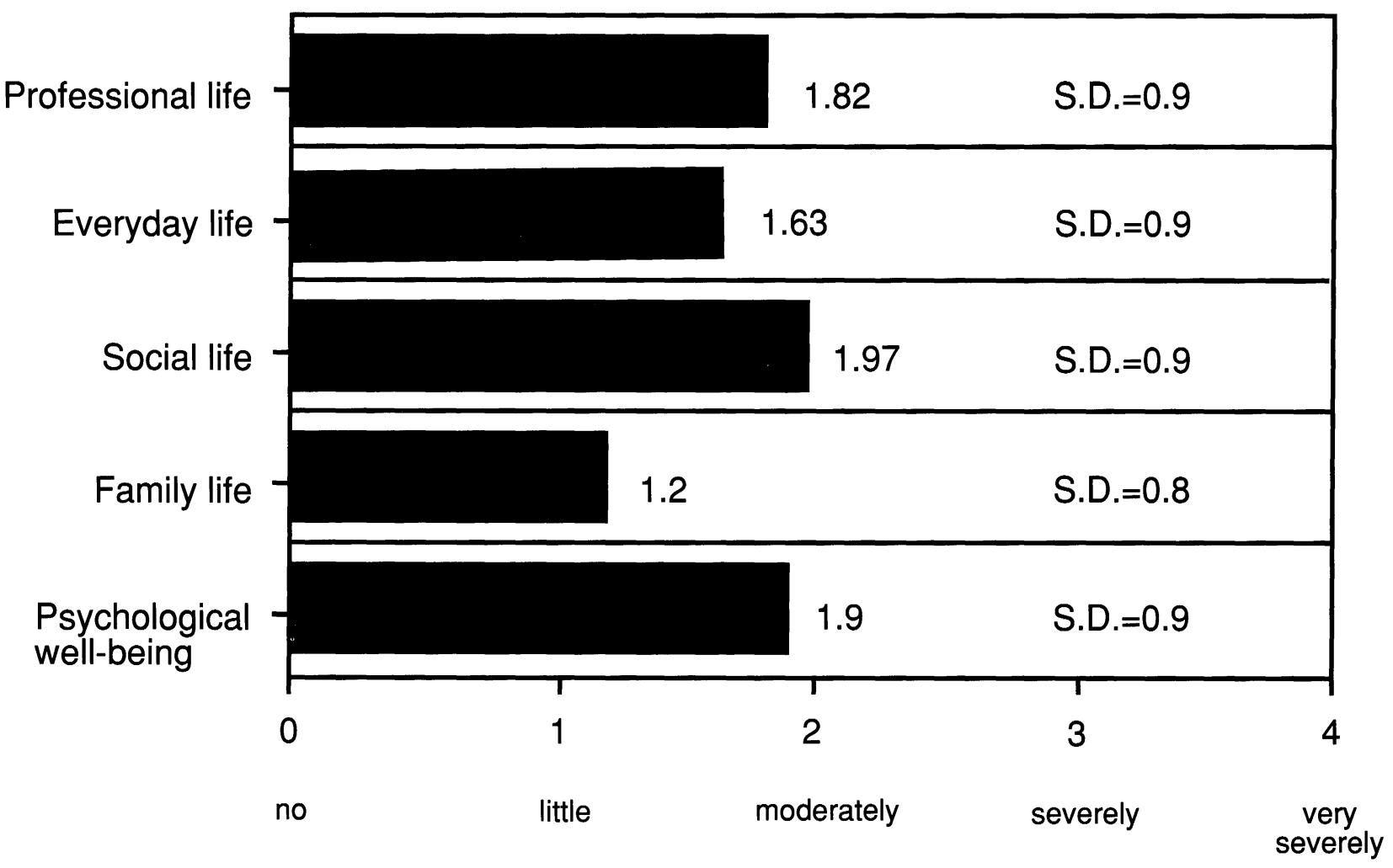

FIG. 1. Psychosocial changes in different areas of life. Mean scores and standard deviations.

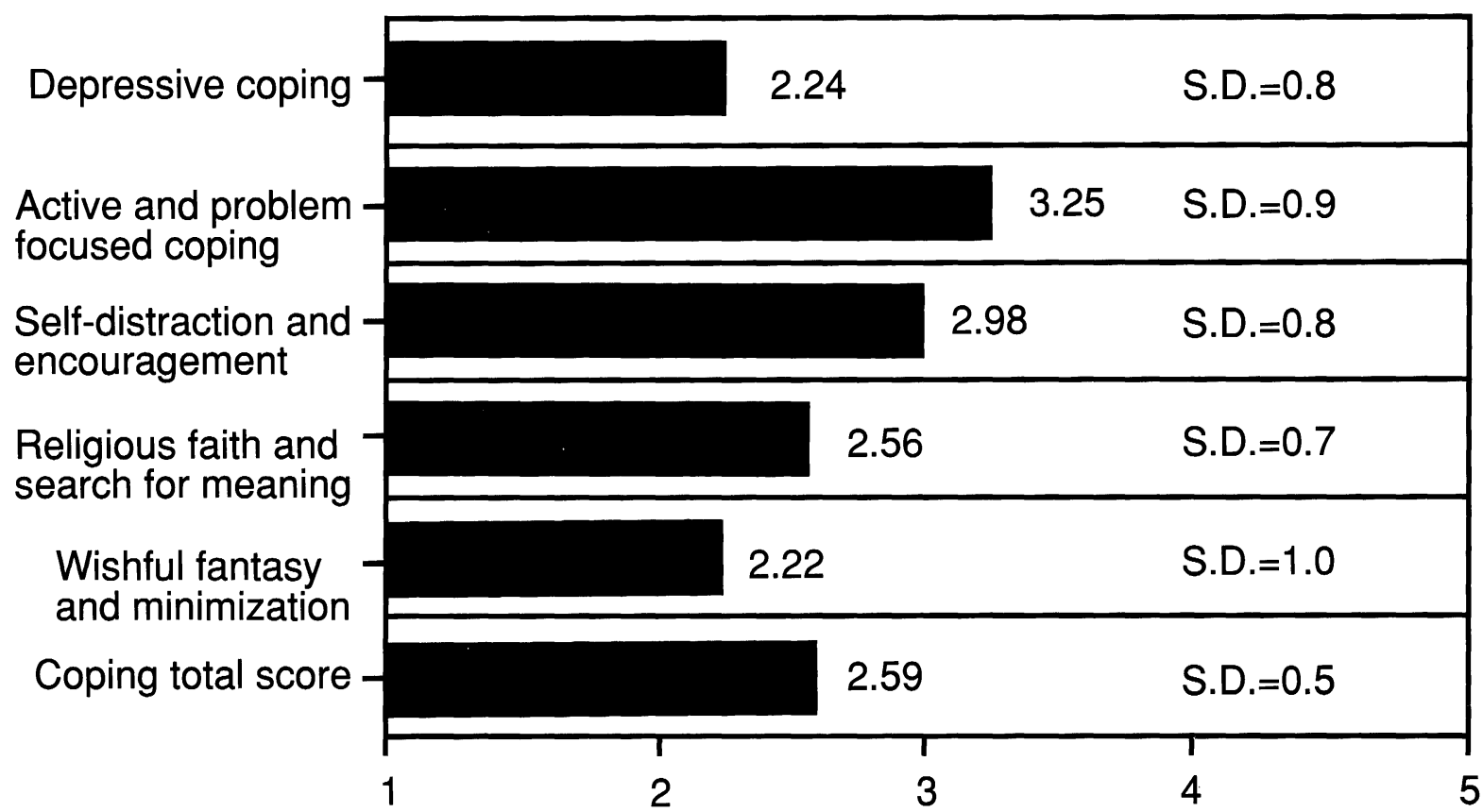

FIG. 2. FKV coping scales, mean scores and standard deviations.

describes cognitive-emotional elements of depression. The scale minimization and wishful thinking comprises cognitive defence strategies such as not wanting to recognize a painful experience or to minimize its significance.

Female patients applied active problem-focused Behavioural Neurology . Vol 9 . 1996

91 
coping strategies more often than male patients $(p<0.5)$; however the total coping activity did not differ significantly between the sexes.

Interrelations of the measures. Table I shows correlations between psychosocial changes, demographic variables, signs, symptoms and coping. The correlations between symptoms (pain, muscle tension and head deviation) and psychosocial changes are highly significant throughout. The correlations between signs and psychosocial changes are markedly weaker. However retro/anterocollis shows a substantial correlation with changes in those areas of life which specifically require functional capacities (e.g. professional and everyday life). This may indicate that retro/anterocollis is more functionally disabling than rotational or even tilting torticollis. The correlations between demographic variables and psychosocial changes are negligible, whereas the correlations between coping strategies and psychosocial changes show close associations between depressive coping and psychosocial changes in all areas of life.

Table II shows the correlations between coping, demographic variables, signs and symptoms. Age correlates significantly with two of the coping strategies, namely religious faith and search for meaning. The signs do not correlate with coping at all. The correlations between symptoms and coping are low. However, some significant positive correlations emerge with depressive coping.

Predictors of psychosocial changes. In order to investigate predictors of psychosocial changes, a stepwise multiple regression analysis was calculated. Independent variables were the signs (deviation of the head in different planes and the TSUI-index, the symptoms (deviation of the head, muscle tension, tremor and pain) and coping (five coping strategies).

The five area-of-life-scales (sum scores) were the criterion variables; missing data were pair-wise excluded. Table III shows the results. The predictive power of the equations ranges between $r^{2}=0.33$ for family life and $r^{2}=0.50$ for everyday life.

In those areas where functional impairment is of particular importance, the symptoms pain and muscle tension accounted for the highest variance and enter the equation first, whereas depressive coping emerged as the most important factor for changes in family and social life and for psychological wellbeing.

The deviation of the head (self-reported) entered four equations. This variable seems particularly important for social life, accounting for $15 \%$ of the variance.
The signs played only a minor role for the psychosocial changes accounting for a low variance in two equations.

In summary, psychosocial changes in ST seem to depend more on symptoms than on signs. With regard to coping, a depressive coping style in particular contributes to the experience of life as more severely impaired due to the illness.

\section{DISCUSSION}

The results of the study may be summarized under two categories, coping and psychosocial changes.

\section{Coping}

The majority of ST patients apply active, problemfocused coping strategies and strategies such as selfdistraction and encouragement, religious faith and search for meaning.

Other studies reported a preference of cognitive and emotion-focused coping over active instrumental coping styles in ST (Jahanshahi, 1991). Different rating instruments may account for the discrepant results. Compared to those studies using the same questionnaire (FKV), for example studies on cancer, end-stage renal disease and multiple sclerosis, the coping strategies in ST equal those of other patient groups suffering from chronic illnesses (Muthny et al., 1992).

The correlations of coping strategies with sex, age and the severity of illness reported in the literature differ (Normann and Kordy, 1991; Muthny, 1992; Voll et al., 1992). In agreement with Jahanshahi (1991) we found that female torticollis patients generally used more coping strategies than men, but this was statistically significant only for one coping style, namely active, problem-focused coping. No signifcant correlations were found between the severity of the neurological signs and coping. This suggests that the preferred coping strategies are not determined by characteristics of the neurological condition.

However substantial correlations emerged between the neurological symptoms and coping, most pronounced for pain and depressive coping. This confirms the results of Jahanshahi (1991), who also reported a significant correlation between pain and maladaptive coping. Although in both studies the correlations between dysfunctional coping strategies and pain were not high ( 0.30 and 0.35 respectively), it can be concluded that pain and depressive coping are likely to interact and facilitate each other.

As has been reported in other studies on coping (Muthny et al., 1992; Harrer et al., 1993), religious faith and search for meaning are more widely used 
TABLE I. Correlations between psychosocial changes (scales of the FQD) signs (neurological assessment) symptoms (self-reported) and coping (FKV)

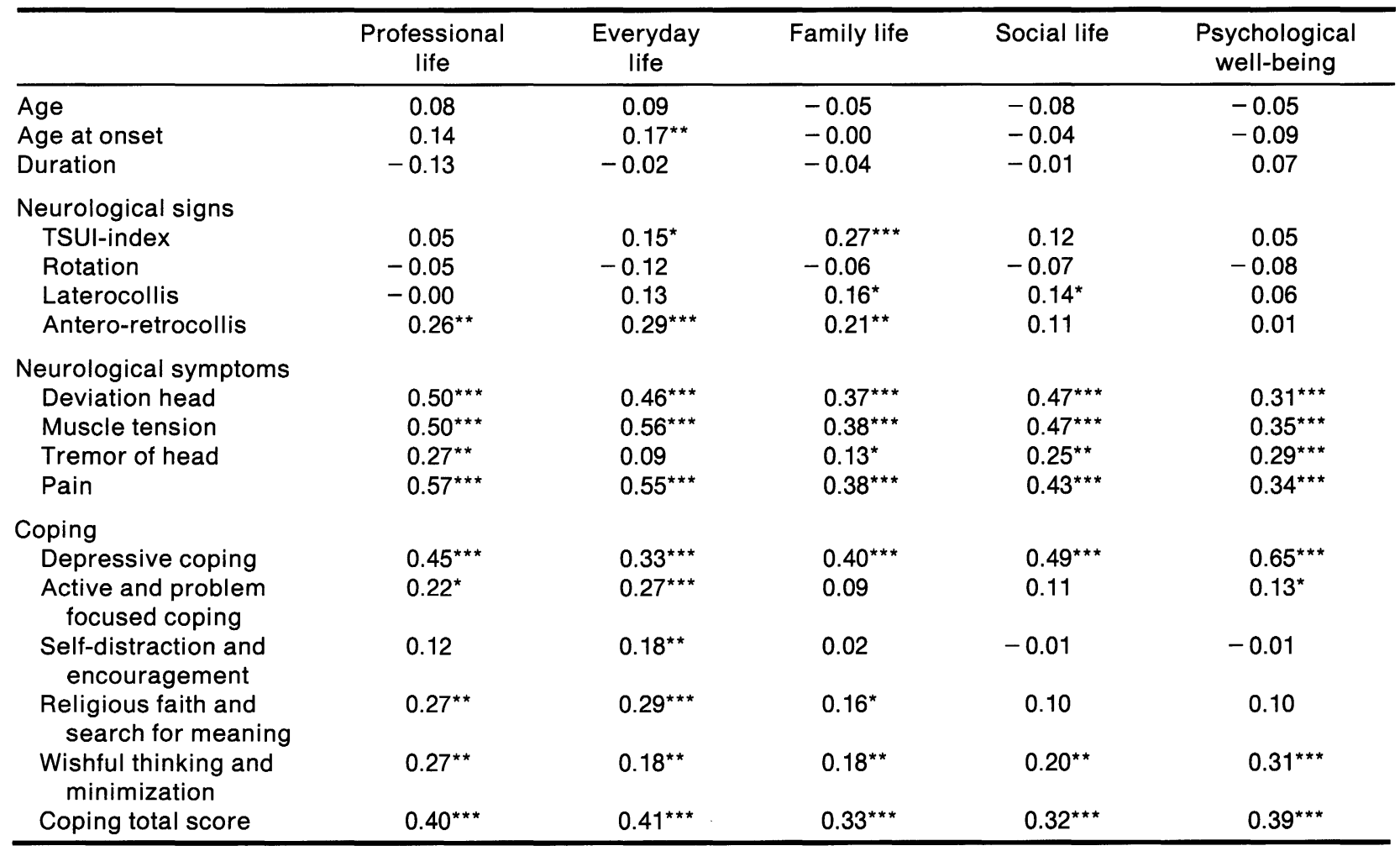

${ }^{\star} p<0.05 ;{ }^{\star \star} p<0.01 ;{ }^{\star \star \star} p>0.001$. The correlations between psychosocial changes and the neurological symptoms are highly significant throughout, whereas the correlations between psychosocial changes and the neurological signs are weak.

TABLE II. Correlations between coping (FKV), demographic variables, signs (neurological assessment) and symptoms (self-reported)

\begin{tabular}{|c|c|c|c|c|c|c|}
\hline & $\begin{array}{l}\text { Depressive } \\
\text { coping }\end{array}$ & $\begin{array}{l}\text { Active and } \\
\text { problem } \\
\text { focused } \\
\text { coping }\end{array}$ & $\begin{array}{c}\text { Self- } \\
\text { distraction } \\
\text { and } \\
\text { encouragement }\end{array}$ & $\begin{array}{l}\text { Religious } \\
\text { faith and } \\
\text { search for } \\
\text { meaning }\end{array}$ & $\begin{array}{c}\text { Wish- } \\
\text { fulfilling } \\
\text { fantasy and } \\
\text { minimization }\end{array}$ & $\begin{array}{l}\text { Coping } \\
\text { total } \\
\text { score }\end{array}$ \\
\hline $\begin{array}{l}\text { Age } \\
\text { Age at onset } \\
\text { Duration }\end{array}$ & $\begin{array}{l}-0.15^{\star \star} \\
-0.17^{\star \star} \\
0.00\end{array}$ & $\begin{array}{l}0.11^{\star} \\
0.09 \\
0.02\end{array}$ & $\begin{array}{r}0.03 \\
-0.03 \\
0.05\end{array}$ & $\begin{array}{l}0.26^{\star \star \star} \\
0.15^{\star \star} \\
0.16^{\star \star}\end{array}$ & $\begin{array}{r}0.05 \\
0.07 \\
-0.06\end{array}$ & $\begin{array}{l}0.09 \\
0.03 \\
0.06\end{array}$ \\
\hline $\begin{array}{l}\text { Neurological signs } \\
\text { TSUl-index } \\
\text { Rotation } \\
\text { Laterocollis } \\
\text { Antero-retrocollis }\end{array}$ & $\begin{array}{r}0.02 \\
-0.03 \\
-0.06 \\
0.06\end{array}$ & $\begin{array}{r}0.05 \\
0.04 \\
0.00 \\
-0.12^{*}\end{array}$ & $\begin{array}{r}0.10 \\
0.08 \\
-0.04 \\
0.00\end{array}$ & $\begin{array}{l}0.10 \\
0.03 \\
0.14 \\
0.06\end{array}$ & $\begin{array}{r}0.10 \\
-0.01 \\
0.05 \\
0.06\end{array}$ & $\begin{array}{l}0.10 \\
0.01 \\
0.02 \\
0.10\end{array}$ \\
\hline $\begin{array}{l}\text { Neurological symptom } \\
\text { Deviation head } \\
\text { Muscle tension } \\
\text { Tremor of head } \\
\text { Pain }\end{array}$ & $\begin{array}{l}0.18^{\star \star} \\
0.22^{\star \star \star} \\
0.16^{\star \star} \\
0.30^{\star \star \star}\end{array}$ & $\begin{array}{l}0.03 \\
0.19^{\star *} \\
0.14^{\star} \\
0.21^{\star \star \star}\end{array}$ & $\begin{array}{l}0.00 \\
0.09 \\
0.09 \\
0.11^{\star}\end{array}$ & $\begin{array}{l}0.13^{\star} \\
0.16^{\star \star} \\
0.03 \\
0.16^{\star \star}\end{array}$ & $\begin{array}{l}0.08 \\
0.18^{\star *} \\
0.03 \\
0.09\end{array}$ & $\begin{array}{l}0.13 \\
0.26^{\star \star \star} \\
0.19^{\star \star} \\
0.29^{\star \star \star}\end{array}$ \\
\hline
\end{tabular}

${ }^{\star} p<0.05 ;{ }^{* \star} p<0.01 ;{ }^{* \star *} p<0.001$. Significant correlations between depressive coping and the neurological symptoms, no correlations however, with the neurological signs. 
TABLE III. Multiple regression analysis with psychosocial changes (scales of the FQD) as dependant variables

\begin{tabular}{llcc}
\hline Criterion variables & Predictor variables & Betaweight & $r^{2}$ \\
\hline Professional life & 1. Pain & 0.36 & 0.33 \\
& 2. Depressive coping & 0.29 & 0.41 \\
3. Deviation head & 0.29 & 0.49 \\
Everyday life & 1. Muscle tension & 0.22 & 0.31 \\
& 2. Pain & 0.24 & 0.37 \\
& 3. Antero-retrocollis & 0.20 & 0.42 \\
& 4. Religious faith and search for meaning & 0.18 & 0.46 \\
Family life & 5. Depressive coping & 0.15 & 0.48 \\
& 6. Deviation head & 0.16 & 0.50 \\
& 1. Depressive coping & 0.31 & 0.16 \\
Social life & 2. Deviation head & 0.18 & 0.25 \\
& 3. TSUl-index & 0.22 & 0.30 \\
Psychological well-being & 4. Muscle tension & 0.19 & 0.33 \\
& 1. Depressive coping & 0.39 & 0.24 \\
& 2. Deviation head & 0.27 & 0.39 \\
& 3. Muscle tension & 0.23 & 0.43 \\
& 1. Depressive coping & 0.39 & 0.42 \\
\end{tabular}

Neurological symptoms rather than neurological signs predict psychosocial changes in different areas of life.

by older patients. Our data confirm a positive correlation between age and these two coping strategies.

\section{Psychosocial changes}

The results of the study show that ST may entail severe psychosocial changes. Social life in particular is affected. This is in line with other reports in the literature (Matthews et al., 1978; Rentrop and Straschill, 1982; Halbgewachs and Aschoff, 1992; van Herwaarden et al., 1994). In contrast, family life seems slightly less impaired. However, psychosocial changes do not occur in all patients equally. The question arises to what factors differences might be attributed.

Although depressive coping is not very common among ST patients as compared to active, problemfocused coping, it is of particular importance in predicting psychosocial changes: in the regression analysis, depressive coping entered in all equations and accounted for the highest variance for three areas of life, psychological well-being, social life and family life. The neurological symptoms turned out to be important predictors too, entering all equations and accounting for the highest variance in professional life and in everyday life. In contrast the neurological signs were only of minor significance in predicting psychosocial changes.

Psychosocial changes do not occur automatically as a consequence of ST (Rondot et al., 1991; Halbgewachs and Aschoff, 1992). Coping strategies (Halbgewachs and Aschoff, 1992) and the "personal manage- ment of the disease" (Rondot et al., 1991) are important modulating factors. Social support, locus of control and causal attribution (Beutel and Muthny, 1988) as well as personality traits, none of which has been included in this study, may be of relevance too.

The results confirm the importance of coping for psychosocial adjustment in chronic diseases (Felton and Revenson, 1984; Felton et al., 1984; Friedman et al., 1988). However, it is important to point out that coping and psychosocial adjustment are interdependent (Heim et al., 1983; Lazarus et al., 1985). There is no unidirectional causal relationship between the two.

A more extensive analysis of the links between coping processes and psychosocial adjustment as described in various theoretical models (Heim, 1988; Lazarus and Folkman, 1984) is beyond the scope of this study. Investigation of these issues would require other than cross-sectional data. Nevertheless the presented results provide sufficient evidence to assume a rather close correlation between coping and psychosocial changes in ST.

Concerning treatment it may be concluded that the subjective awareness of the physical symptoms is strongly influenced by psychological processes (Weisenberg, 1977). Psychotherapeutic treatment might help to improve the patients' management of their symptoms and thus may result in a better social adjustment. Changes in maladaptive coping strategies may help to reduce the psychosocial changes. The

94 Behavioural Neurology . Vol 9.1996 
importance of coping for psychosocial adjustment therefore supports the argument for psychotherapy in ST.

Several authors have pointed out that ST patients applying "adaptive" coping strategies show a more favourable course than those applying maladaptive coping strategies (Rentrop and Straschill, 1982; Witzmann et al., 1984; Marten and Thomä, 1988; Halbgewachs and Aschoff, 1992). A concentration of treatment on coping might therefore help to improve not only the psychosocial adjustment but also the course of the disease.

\section{REFERENCES}

Beutel M and Muthny FA (1988) Konzeptualisierung und klinische Erfassung von Krankheitsverarbeitung - Hintergrundtheorien Methodenprobleme und künftige Möglichkeiten. Psychotherapie, Psychosomatik, Medizinische Psychologie, 38, 19-27.

Felton BJ and Revenson TA (1984) Coping with chronic illness: a study of illness contrability and the influences of coping strategies on psychological adjustment. Journal of Consulting and Clinical Psychology, 3, 343-353.

Felton BJ, Revenson TA and Hinrichsen GA (1984) Stress and coping in the explanation of psychological adjustment among chronically ill adults. Social Science and Medicine, 18, 889-898.

Folkman S and Lazarus RS (1980) An analysis of coping in a middle-aged community sample. Journal of Health and Social Behavior, 21, 219-239.

Friedman LC, Baer PE, Lewy A, Lane M and Smith FE (1988) Predictors of psychosocial adjustment to breast cancer. Journal of Psychosocial Oncology, 6, 75-94.

Halbgewachs FJ and Aschoff JC (1992) Chronischer Verlauf des idiopathischen Tortikollis, Wie bewältigen die Patienten ihre Krankheit? Therapiewoche Neurologie Psychiatrie, 6, 426-435.

Harrer ME, Mosheim R, Richter R, Walter MH and Kemmler G (1993) Coping und Lebenszufriedenheit bei Patienten mit M. Hodgkin in Remission. Ein Beitrag zur Frage der Adaptivität von Coping-Prozessen. Psychotherapie, Psychosomatik, Medizinische Psychologie, 43, 121-132.

van Herwaarden GMFM, Anten HW, Hogduin CAL, Niewold JUR, Roos RAC, Speelman JD, van Weerden TW and Horstink MWIM (1994) Idiopathic spasmodic torticollis: a survey of the clinical syndromes and patients experiences. Clinical Neurology and Neurosurgery, 96, 222-225.

Heim E (1988) Coping und Adaptivität: Gibt es geeignetes oder ungeeignetes Coping? Psychotherapie, Psychosomatik, Medizinische Psychologie, 38, 8-18.

Heim E, Augustiny K and Blaser A (1983) Krankheitsbewältigung (Coping) - ein integriertes Modell. Psychotherapie, Psychosomatik, Medizinische Psychologie, 33, 35-40.

Heinen F, Scheidt CE, Nickel T, Rayki O, Wissel J, Poewe W, Benecke R, Arnold G, Oertel W, Dengler R and
Deuschl G (1996) Spasmodic torticollis - a multicentre study on behavioural aspects II: signs, symptoms and course. Behavioural Neurology, 9, 81-88.

Jahanshahi M (1991) Psychosocial factors and depression in torticollis. Journal of Psychosomatic Research, 35, 493-507.

Jahanshahi M and Marsden CD (1988) Depression in torticollis: a controlled study. Psychological Medicine, 18, 925-933.

Jahanshahi M and Marsden CD (1990a) Body concept, disability, and depression in patients with spasmodic torticollis. Behavioural Neurology, 3, 117-131.

Jahanshahi $\mathbf{M}$ and Marsden CD (1990b) A longitudinal follow-up study of depression, disability, and body concept in torticollis. Behavioural Neurology, 3, 233-246.

Lazarus RS and Folkman S (1984) Stress, Appraisal and Coping. Springer, Berlin, Heidelberg.

Lazarus RS, de Longis A, Folkman S and Gruen R (1985) Stress and adaptational outcomes. The problem of confounded measures. American Psychologist, 40, 770-779.

Marten RF, Thomä H (1988) Zur Entstehung und Verlauf des Torticollis spasticus. Fundamenta Psychiatrica, 4, 283-291.

Matthews WB, Beasley P, Parry-Jones W and Garland G (1978) Spasmodic torticollis: a combined clinical study. Journal of Neurology, Neurosurgery, and Psychiatry, 41, 485-492.

Muthny FA (1992) Krankheitsverarbeitung im Vergleich von Herzinfarkt-, Dialyse- und MS-Patienten. Zeitschrift für Klinische Psychologie, 4, 372-391.

Muthny FA, Bechtel M and Spaete M (1992) Laienätiologin und Krankheitsverarbeitung bei schweren körperlichen Erkrankungen. Eine empirische Vergleichsstudie mit Herzinfarkt-, Krebs-, Dialyse und MS-Patientinnen. Psychotherapie, Psychosomatik, Medizinische Psychologie, 42, 41-53.

Normann D and Kordy H (1991) Coping bei Morbus Crohn-Patienten unter differentieller Perspektive: Ein Beitrag zur Spezifitätsdiskussion. Psychotherapie, Psychosomatik, Medizinische Psychologie, 41, 11-21.

Rentrop E and Straschill M (1982) Verlaufsformen des idiopathischen Torticollis spasmodicus. Aktuelle Neurologie, 9, 150-154.

Rondot P, Marchand MP and Dellatolas G (1991) Spasmodic torticollis - review of 220 patients. Canadian Journal of the Neurologic Sciences, 18, 143-151.

Scheidt CE, Rayki O, Nickel T, Heinen F, Wissel J, Poewe W, Benecke R, Arnold G, Oertel W, Dengler R and Deuschl G (1966) Spasmodic torticollis - a multicentre study on behavioural aspects I: introduction and methods. Behavioural Neurology, 9, 25-31.

Voll R, Höcker B, Krumm B and Poustka F (1992) Krankheitsverarbeitung bei chronisch kranken Jugendlichen und jungen Erwachsenen-eine empirische Untersuchung. Psychotherapie, Psychososmatik, Medizinische Psychologie, 42, 332 338.

Weisenberg M (1977) Pain and pain control. Psychological Bulletin, 84, 1008-1044.

Witzmann A, Quatember R, Valencak E and Grunert V (1984) Neuropsychologische Aspekte des Torticollis spasticus. Wiener Medizinische Wochenschrift, 134, 45-48. 


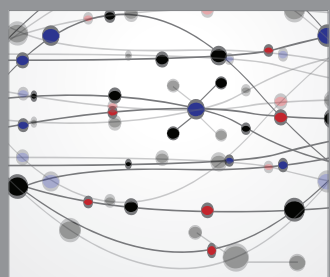

The Scientific World Journal
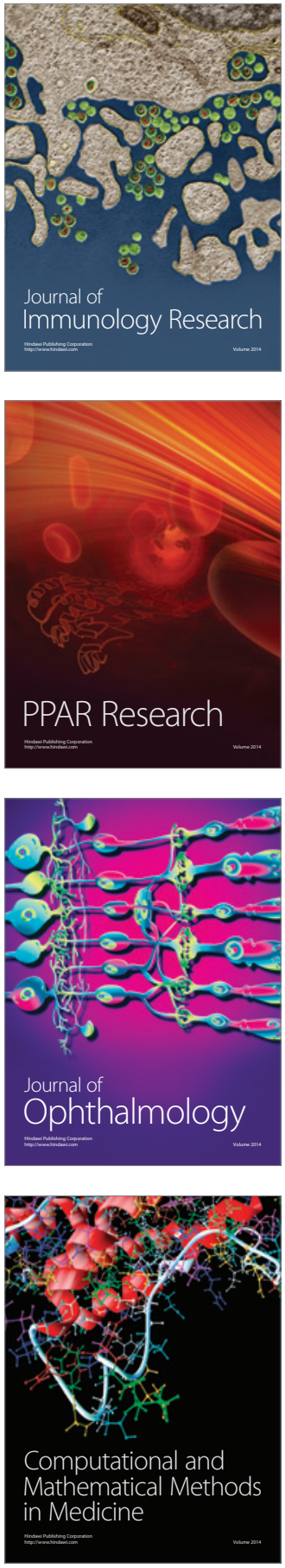

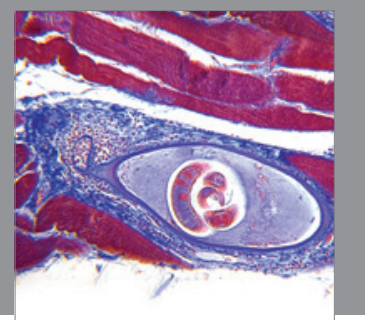

Gastroenterology

Research and Practice
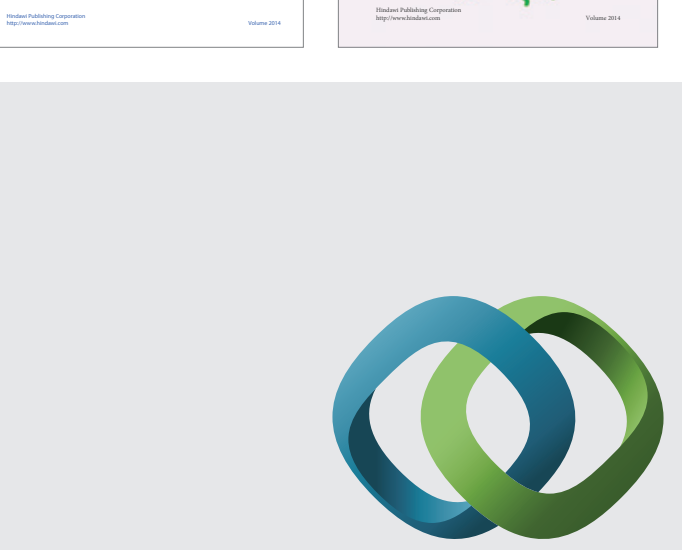

\section{Hindawi}

Submit your manuscripts at

http://www.hindawi.com
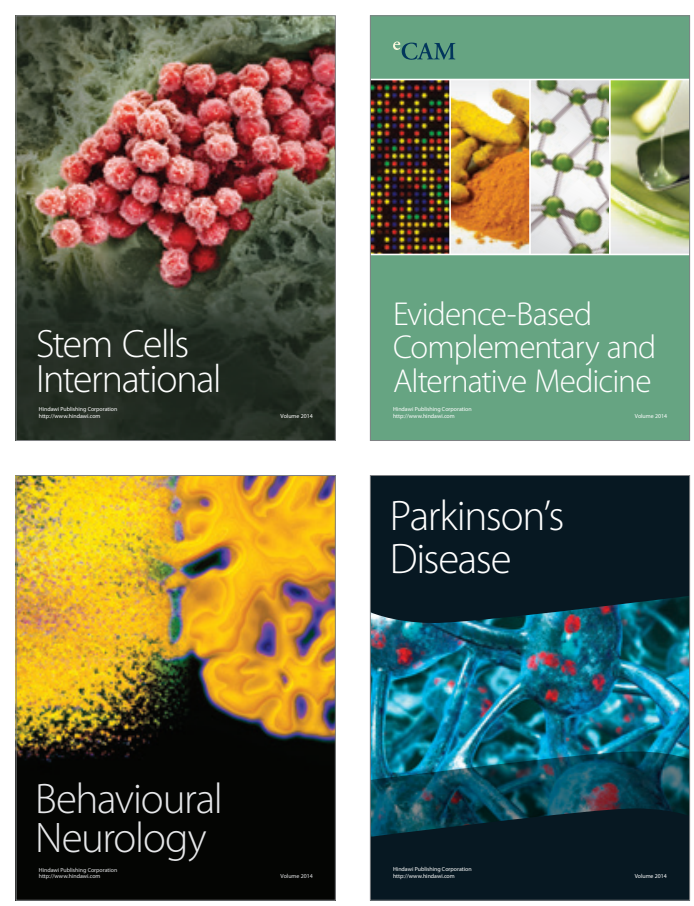

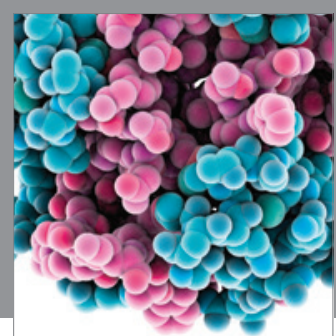

Journal of
Diabetes Research

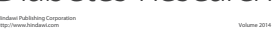

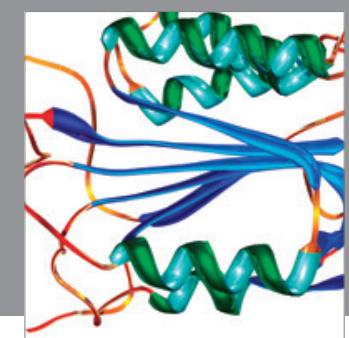

Disease Markers
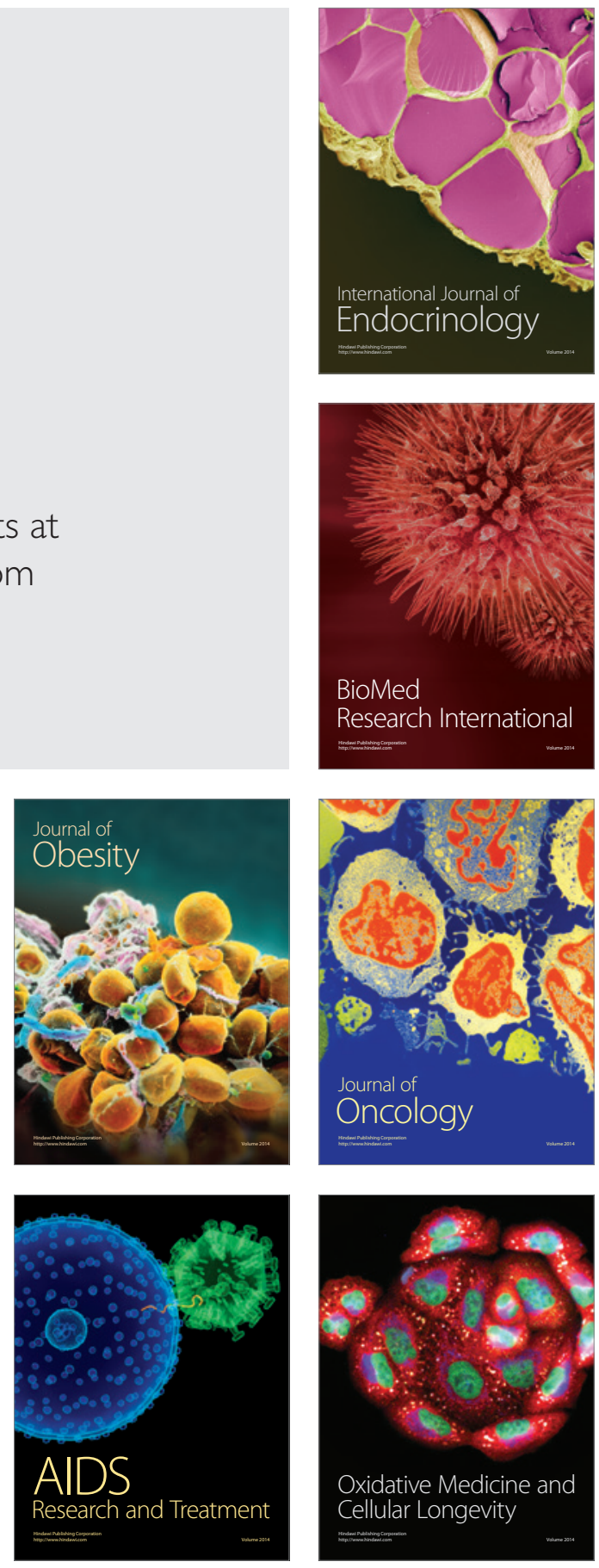